\title{
Human Disorders of Axon Guidance
}

\author{
Alicia A. Nugent ${ }^{a, b}$, Adrianne L. Kolpak ${ }^{a, c}$, and Elizabeth C. Engle ${ }^{a, c, d, e,{ }^{*}}$ \\ aDepartment of Neurology, F.M. Kirby Neurobiology Center, and The Manton Center for Orphan \\ Disease Research, Children's Hospital Boston, CLS14, 300 Longwood Ave, Boston, MA 02115, \\ USA \\ bProgram in Neuroscience, Harvard Medical School, Boston, MA 02115, USA \\ 'Department of Neurology, Harvard Medical School, Boston, MA 02115, USA \\ dDepartment of Ophthalmology, Harvard Medical School, Boston, MA 02115, USA \\ eHoward Hughes Medical Institute, Chevy Chase, MD 20815, USA
}

\begin{abstract}
Axon pathfinding is essential for the establishment of proper neuronal connections during development. Advances in neuroimaging and genomic technologies, coupled with animal modeling, are leading to the identification of an increasing number of human disorders that result from aberrant axonal wiring. In this review, we summarize the recent clinical, genetic and molecular advances with regard to three human disorders of axon guidance: Horizontal gaze palsy with progressive scoliosis, Congenital mirror movements, and Congenital fibrosis of the extraocular muscles, Type III.
\end{abstract}

\section{Introduction}

The field of axon guidance has expanded dramatically over the past few decades. Animal models and in vitro neuronal culture techniques have fostered the discovery of many molecules that are essential for the correct guidance and target innervation of exploring axonal processes during neurodevelopment. Surprisingly, there are still relatively few identified human disorders resulting from axon guidance defects, and most of the identified disorders are rare. This does not necessarily mean that aberrant axon guidance does not cause common human disorders, but rather that, until recently, technology has hindered the identification of subtle white matter tract miswiring in the human nervous system. The advent of high-resolution magnetic resonance imaging (MRI) and diffusion tensor imaging (DTI), along with advances in genetic technologies, have now helped to define the first series of human genetic disorders of axon guidance [1,2], and will likely contribute to the discovery of many additional axon guidance disorders in the future. This article is an update to the Engle 2010 review [1] and predominantly highlights recent work that contributes to the further understanding of Horizontal gaze palsy with progressive scoliosis (HGPPS), Congenital mirror movements (CMM), and Congenital fibrosis of the extraocular muscles, Type III (CFEOM3).

\footnotetext{
(C) 2012 Elsevier Ltd. All rights reserved.

*Author for correspondence: Elizabeth.Engle@ childrens.harvard.edu; Phone: 617-919-4030; FAX: 617-919-2768.
}

Publisher's Disclaimer: This is a PDF file of an unedited manuscript that has been accepted for publication. As a service to our customers we are providing this early version of the manuscript. The manuscript will undergo copyediting, typesetting, and review of the resulting proof before it is published in its final citable form. Please note that during the production process errors may be discovered which could affect the content, and all legal disclaimers that apply to the journal pertain. 


\section{Horizontal Gaze Palsy with Progressive Scoliosis}

Horizontal gaze palsy with progressive scoliosis (HGPPS) is a rare disorder that results from axonal midline crossing defects of specific populations of neurons in the hindbrain and possibly spinal cord. The disorder presents with congenital bilateral absence of horizontal eye movement. During childhood, patients develop debilitating scoliosis. There are reported delays in motor development, but otherwise patients are intellectually and physically normal, and mirror movements have not been reported $[3,4]$. This autosomal recessive disorder was described as early as 1970 [5], but it was not until 2004 that loss of function mutations in the axon guidance receptor ROBO3 were found to underlie HGPPS [3,6-11].

MRI, functional MRI, DTI, and evoked potential studies of HGPPS patients reveal a normal corpus callosum [12-15], but a virtually pathognomonic hindbrain malformation that correlates with failure of the corticospinal tracts (CST) and dorsal column tracts to decussate in the hindbrain (Fig. 1) [4,6,10,12-15]. A HGPPS patient harboring ROBO3 mutations who suffered a stroke in the motor cortex resulting in ipsilateral limb weakness and facial palsy further confirmed uncrossed CST in this disorder [10]. Sensorimotor evoked potential studies in a second patient revealed ipsilateral CST but partial crossing of the dorsal column tracts, suggesting there may be some variability in midline crossing defects within and between patients [4]. DTI of HGPPS patients revealed that cerebellar tracts are also uncrossed or abnormally located, which may contribute to progressive scoliosis $[12,14,15]$. FMRI and brainstem auditory evoked potential (BAEP) studies indicate that HGPPS patients also have abnormal activation of auditory pathways $[4,13]$. Two patients exhibited highfrequency hearing loss in the right ear, which may contribute to abnormal BAEPs [4]. However, if these findings are not a result of unilateral sensorineural hearing loss, they may reflect auditory circuit rewiring in HGPPS patients. Future advances in imaging technology should help continue to define axon guidance abnormalities in this disorder.

Robo3 (Rig1) is a transmembrane protein predominantly expressed in hindbrain and spinal cord commissural axons during embryonic development, and exists in two splice variants, Robo3.1 and Robo3.2 [6,16-18]. Slit is expressed by the floorplate and normally transmits a repellent response upon binding to Robo1 and Robo2 receptors expressed on crossing commissural axons [19]. As commissural axons approach the floorplate, Robo3.1 is thought to interfere with Slit repulsion to allow midline crossing [17,18]. Once axons cross the floorplate, Robo3.1 is quickly downregulated and Robo1, Robo2, and Robo3.2 transmit responses that propel growing axons away from the midline to prevent recrossing $[17,18]$. ROBO3 mutations underlying HGPPS include nonsense, frameshift, splice site, and missense changes that are spread across the gene [3,6-11]. To date, none map to residues that would alter expression of one splice variant over the other, and thus HGPPS mutations are predicted to result in loss of both $\mathrm{ROBO} 3.1$ and $\mathrm{ROBO} 3.2$ function.

Studies of Robo $^{-/}$mice have provided extensive insights into the molecular mechanisms and anatomical miswiring underlying HGPPS. In $\mathrm{Robos}^{-/-}$mice, commissural axons fail to cross both the spinal cord and hindbrain midline at E11.5 [17]. Robo ${ }^{-/-}$die at birth, however, and it has not been determined whether the CST, which decussates just prior to birth, is also uncrossed. Interestingly, Robo3 does not appear to be expressed in developing upper motor neurons, which form the CST [16,20], although a more detailed spatiotemporal expression analysis is needed to formally conclude this. Thus, the lack of CST decussation in HGPPS may be secondary to the failure of earlier populations of commissural neurons to form a midline bridge for CST axons to cross later in development [17,21].

Subsequent studies of $\mathrm{Robo}^{-/-}$mice have identified additional defects in the crossing of cerebellar, auditory, and breathing circuitry [21-24]. Cerebellar neuronal migration, axonal 
and neuronal midline crossing, and nucleus cytoarchitecture are abnormal in $\mathrm{Robo}^{-/}$mice, which further substantiates abnormal cerebellar tracts noted in DTI of HGPPS patients $[12,14,15,25]$. Interestingly, mouse precerebellar neurons require a translational regulatory protein, Musashi1, for protein expression of Robo3.1 and 3.2 in order to permit proper cerebellar neuron and axonal midline crossing events [26]. If Musashi1 proves to have a similar regulatory role in human hindbrain horizontal gaze circuitry, its corresponding gene, MSI1, would be an interesting candidate disease gene for patients with horizontal gaze palsy with or without scoliosis who do not harbor mutations in $R O B O 3$. It is particularly relevant for patients with additional clinical or imaging evidence of central nervous system guidance errors, as the $\mathrm{msil}^{-/-}$mouse develops hydrocephalus and has variable agenesis of the corpus callosum with Probst's bundles [27].

To directly investigate the etiology of horizontal gaze palsy in HGPPS, Renier et al [24] used a conditional knockout approach in mice to selectively remove Robo3 expression in rhombomeres 3 and 5 of the hindbrain (Robo3:Krox20Cre). These animals survive, and consistent with human MRI data [6,28], the abducens motor neurons in Robo3:Krox20Cre mice form normally and axons appear to correctly innervate the lateral rectus muscle [24]. However, there is reduced axonal midline crossing at the level of the abducens nucleus and a paucity of projections between the abducens nucleus and contralateral oculomotor nucleus, with occasional sparse ipsilateral projections. This suggests that the medial longitudinal fasciculus and the paramedian pontine reticular formation interneuron populations, which cross the midline of the hindbrain to control oculomotor and abducens motor nuclei and permit horizontal gaze, are unable to cross in Robo3:Krox20Cre mice, resulting in disrupted lateral and medial gaze. Indeed, horizontal eye movements are limited in Robo3:Krox20Cre mice, while vertical gaze is preserved [24], recapitulating eye motility defects seen in HGPPS patients.

Similar to human studies, BAEPs were also found to be abnormal in $\mathrm{Robo}^{-/-}$mice. Closer anatomical investigation revealed that axons from the anteroventral cochlear nucleus, the main auditory projections that decussate in the hindbrain, do not cross in $R o b o 3^{-/}$mice, but rather form ipsilateral Calyx of Held synapses [24]. In addition, Bouvier et al [23] identified asynchronous breathing in P0 Robo ${ }^{-/-}$mice, resulting from an absence of interneuron crossing in the hindbrain. The group hypothesizes that scoliosis in patients could result from asynchronous muscle contraction, however it remains to be determined whether humans with HGPPS breathe asynchronously.

It is remarkable that HGPPS patients have relatively normal gross motor, sensory, and proprioceptive behavior considering human patient imaging and mouse anatomical studies have identified ROBO3/Robo3 as a critical regulator of midline crossing in the hindbrain and spinal cord. This suggests that axons innervate targets correctly, but on the ipsilateral rather than contralateral side of the body, as demonstrated in studies of Robo $^{-/-}$mice $[23,24]$. There is mounting evidence that horizontal gaze palsy results from uncrossed and/or absent oculomotor and abducens internuclear tracts. The etiology of scoliosis remains more elusive, and may arise from the combined absence of CST, reticulospinal, and/or cerebellar tract crossing events, or perhaps asynchronous breathing.

\section{Congenital mirror movements}

Congenital mirror movements (CMM) are a synkinesis in which pathological involuntary movements on one side of the body occur simultaneously with intentional movements on the contralateral side. Mirror movements typically occur in the fingers, hands, and forearms and can be observed in young children, but normally disappear by 7 years of age unless there is underlying pathology $[29,30]$. There are two primary hypotheses as to the anatomic correlate 
of pathologic CMM. First, fMRI data has supported aberrant signaling across the corpus callosum, resulting in decreased interhemispheric inhibition of the contralateral motor cortex [31]. Second, transcanial magnetic stimulation (TMS) studies have supported either incomplete decussation of the CST, or abnormal distal branching of axons within the contralateral CST, such that projections from the primary motor cortex synapse simultaneously on both ipsilateral and contralateral interneurons or motor neurons within the spinal cord [29,32-34].

CMM occurs as a component of various syndromes, including X-linked Kallmann syndrome and some forms of Joubert syndrome [35-37]. Non-syndromic, isolated CMM also occurs, and can be sporadic or segregate as an autosomal dominant trait with incomplete penetrance. Recently, heterozygous mutations in the $D C C$ gene were reported to underlie isolated CMM in 3 unrelated families of French-Canadian, Iranian and Italian descent [34,38]. Affected family members have MM primarily in the hands and fingers, with only a few reporting lower extremity involvement or disability as a result of the MM. Several individuals harboring heterozygous $D C C$ mutations are reported to have normal brain MRI scans without corpus callosal or hindbrain abnormalities [34]. TMS studies of affected individuals harboring $D C C$ mutations reveal simultaneous bilateral muscle contractions, with no latency in muscle response from either side, supporting the presence of both ipsilateral and contralateral CST, or aberrant axonal branching of CST axons, rather than abnormal signaling across the corpus callosum (Fig. 1) [32,34,38]. Notably, 3 autosomal dominant families and 2 sporadic individuals with CMM do not harbor $D C C$ mutations or deletions, one of which is a large pedigree that does not map to the DCC locus [34,38,39]. Thus, CMM is a genetically heterogeneous disorder, and future studies will likely identify additional causative genes.

The $D C C$ gene encodes an axon guidance receptor that responds to netrin, a wellcharacterized axon guidance cue involved in attractive midline guidance decisions in cortex, brainstem, and spinal cord [2]. DCC mutations identified in all 3 dominant CMM families produce frameshifts and introduce premature stop codons. Two mutations are predicted to truncate the DCC protein near the N-terminus, producing a very short transcript that would encode only a few extracellular immunoglobulin-like domains and would lack the netrin binding, transmembrane, and cytoplasmic domains. As predicted, in vitro data confirms that one mutation significantly decreases netrin binding when expressed in COS-7 cells [34]. It is not known, however, whether the truncated DCC proteins are secreted, sequestered intracellularly, or degraded, or whether the mutant transcripts may be subject to nonsensemediated mRNA decay. The third reported mutation, in exon 26 , is predicted to truncate only the last two intracellular domains (P2 and P3) while retaining the netrin-binding and transmembrane domains [38]. If translated, it would produce a DCC protein lacking the portion of the cytoplasmic domain required for DCC dimerization and netrin-1-induced attractive axonal turning [40]. Given that all CMM patients have indistinguishable phenotypes regardless of their specific mutation, and 2 of the mutations would produce short, truncated proteins lacking most functional domains and unlikely to dimerize with fulllength DCC, it can be argued that the mutations likely result in DCC haploinsufficiency.

The importance of netrin/DCC signaling in axon guidance is highlighted by studies of $\mathrm{Dcc}^{-/}$mice, which die at P0 and exhibit agenesis of the corpus callosum, absence of CST pyramidal decussation, and misprojection of the anterior commissure and spinal commissural axons $[41,42]$. At P0, the CST has only reached the upper cervical spinal cord, and thus it is not known if the CST axons would follow the correct trajectory and synapse on the appropriate motor neurons, albeit ipsilaterally. Notably however, a spontaneous mouse mutant, $D c c^{\text {Kanga }}$, harbors a deletion of $D c c$ exon 29, truncating the protein prior to the last cytoplasmic functional domain (P3), similar to the third heterozygous human mutation that 
truncates both P2 and P3 [38,42]. Unlike $D c c^{-/-}$mice, Dcc Kanga/Kanga mice are viable, possibly because they were studied on a different genetic background. The DccKanga/Kanga exhibit axon guidance defects within the corpus callosum, as well as failed decussation of the CST resulting in aberrant ipsilateral projections [42]. Phenotypically, the mice cannot alternate movement of their hindlimbs and exhibit a hopping gait. While a hopping gait has been offered as the mouse equivalent of human mirror movements, the Dcc Kanga/Kanga mice have fully uncrossed, ipsilateral CST projections. Thus, for the DccKanga/Kanga mice to phenocopy CMM in humans, in which TMS studies reveal simultaneous contralateral and ipsilateral CST innervation, one would need to hypothesize that the ipsilateral CST axons branch within the spinal cord to innervate both ipsilateral and contralateral interneurons and motor neurons. However, it is possible that the mouse hopping gait and human mirror movements are not equivalent. Of note, Dcc Kanga/Kanga mice with hopping gait harbor homozygous, while humans with CMM harbor heterozygous Dcc mutations, and perhaps this dosage effect results in partial CST decussation in humans. If this were the case, analyzing CST decussation in heterozygous Dcc mutant mice may prove informative.

An alternative explanation for the Dcc Kanga/Kanga hopping phenotype is that it results from alterations in the central pattern generator circuitry caused by aberrant commissural interneuron (CIN) migration across the spinal cord midline. In vitro electrophysiological studies show that loss of netrin-1 induces synchronous, rather than alternating, firing in equivalent left and right regions of isolated netrin- $1^{-/-}$spinal cords [43]. A similar synchronous firing phenomenon is observed in spinal cords harvested from mice lacking ephrinB3, EphA4 or alpha2-chimaerin and, in contrast to the netrin-1 ${ }^{-1}$ mouse which dies at $\mathrm{P} 0$, these mice survive and have hopping gaits [44-46]. Additionally, in ephrinB3-/-, EphA $4^{-/-}$, and $C h n 1^{-/-}$mice, both CST and CIN axons aberrantly cross the spinal midline [44-47], though it is not clear whether aberrant CST or CIN, or both, contribute to the synchronous limb movement and hopping gait. It remains to be determined whether CIN and central pattern generator abnormalities exist in $D c c$ mutant mice, and if these pathways exist in humans and are disrupted in CMM. Finally, DCC is also expressed in corpus callosum axons as they cross the midline, and $\mathrm{Dcc}^{-/-}$mice are acollosal [41]. Thus it remains possible that humans with CMM have additional abnormalities in interhemispheric connectivity. It will be interesting to review DTI scans from individuals with CMM who harbor $D C C$ mutations, as this may help to localize the anatomic pathway underlying their mirror movements.

\section{Congenital fibrosis of the extraocular muscles type 3 (CFEOM3) and the TUBB3 syndromes}

CFEOM3 is an autosomal dominant congenital eye movement disorder with variable penetrance. Affected individuals are born with variable unilateral or bilateral ophthalmoplegia, limited vertical ductions, and blepharoptosis (drooping eyelids) (Fig. 2A) $[48,49]$. MRI shows hypoplasia of the oculomotor nerve and the muscles innervated by its superior branch, the levator palpebrae superioris and superior rectus (Fig. 2B) [49,50]. The oculomotor nerve can also aberrantly innervate the lateral rectus muscle, which is normally innervated by the abducens nerve [50]. CFEOM3 can occur in isolation, or in association with facial weakness, progressive axonal sensorimotor polyneuropathy, and/or social and intellectual disabilities. In patients with social and intellectual disabilities, MRI reveals agenesis or hypoplasia of the anterior commissure and corpus callosum, as well as malformed basal ganglia (Fig. 2C-G) [49]. Both isolated and syndromic CFEOM3 result from specific, repetitive heterozygous missense mutations in $T U B B 3$, which encodes the neuronal-specific beta-tubulin isotype III, a subunit of microtubules [49]. 
Tubb3 is expressed in all post-mitotic neurons and is upregulated during the period of axon growth and guidance [51]. A knock-in mouse model harboring the most common TUBB3 mutation, and resulting in the Tubb3 R262C amino acid substitution, recapitulates the human phenotype and confirms misguidance of the oculomotor nerve, corpus callosum, and anterior commissure without alterations in cortical architecture, suggesting a primary defect in axon pathfinding. When modeled in yeast, these mutations increase microtubule stability, alter microtubule dynamics, and a subset also decrease kinesin plus-end movement [49]. Given the pan-neuronal expression of $T U B B 3$, it is not yet clear why certain populations of axons are selectively affected by these mutations. These data suggest, however, that this tubulin isoform may be downstream of a subset of axon guidance receptors, and critical for the cytoskeleton to respond correctly to upstream signaling. Future molecular and functional studies will help to further elucidate the etiology of CFEOM3, and the additional TUBB3 mutation-specific neurologic disorders, referred to as the TUBB3 syndromes.

\section{Conclusion}

HGPPS, CMM, and CFEOM3 are examples of the contribution that human disease can provide for the elaboration of basic scientific principles, and the insight that mouse models provide toward the understanding of human disorders. These disorders arise primarily from axonal midline crossing defects or peripheral nerve misprojections, which are easier to characterize using current research techniques and technologies. Certainly advances in human genetics and sequencing methodologies, technological developments in human neuroimaging, and continued animal model research will foster the characterization of additional human disorders that arise from subtler axon guidance defects. Preliminary research has hinted that axon guidance abnormalities may contribute to schizophrenia, and autism spectrum disorders such as tuberous sclerosis [52-54]. Perhaps high resolution DTI of humans will help to clarify whether axonal targeting abnormalities contribute to these, and other, disorders.

\section{Highlights}

- We review recent advances in understanding three human disorders of axon guidance.

- $R O B O 3$ mutations cause HGPPS and hindbrain/spinal cord midline crossing defects.

- $\quad D C C$ mutations cause congenital mirror movements and likely midline crossing defects.

- $\quad T U B B 3$ mutations cause syndromic strabismus and callosal and cranial nerve defects.

\section{Acknowledgments}

This work was supported by National Institutes of Health NEI R01EY12498. Dr. Engle is an Investigator of the Howard Hughes Medical Institute.

\section{References}

1. Engle EC. Human genetic disorders of axon guidance. Cold Spring Harb Perspect Biol. 2010; 2(3):a001784. [PubMed: 20300212] . ** This is a comprehensive review of additional human genetic disorders of axon guidance. Our review builds upon this article. 
2. Izzi L, Charron F. Midline axon guidance and human genetic disorders. Clin Genet. 2011; 80(3): 226-234. [PubMed: 21692777] .* This a comprehensive review of midline axon guidance, highlighting molecular mechanisms and human disorders.

3. Chan W-M, Traboulsi E, Arthur B, Friedman N, Andrews C, Engle E. Horizontal gaze palsy with progressive scoliosis can result from compound heterozygous mutations in ROBO3. J Med Genet. 2006; 43(3):e11. [PubMed: 16525029]

4. Amoiridis G, Tzagournissakis M, Christodoulou P, Karampekios S, Latsoudis H, Panou T, Simos P, Plaitakis A. Patients with horizontal gaze palsy and progressive scoliosis due to ROBO3 E319K mutation have both uncrossed and crossed central nervous system pathways and perform normally on neuropsychological testing. J Neurol Neurosurg Psychiatry. 2006; 77(9):1047-1053. [PubMed: 16772357]

5. Dretakis E. Familial idiopathic scoliosis associated with encephalopathy in three children of the same family. Acta orthop Hell. 1970; 22:51-55.

6. Jen JC, Chan WM, Bosley TM, Wan J, Carr JR, Rub U, Shattuck D, Salamon G, Kudo LC, Ou J, Lin DD, et al. Mutations in a human ROBO gene disrupt hindbrain axon pathway crossing and morphogenesis. Science. 2004; 304(5676):1509-1513. [PubMed: 15105459] . ** This article was the first to establish that autosomal recessive mutations in $R O B O 3$ cause HGPPS. MRI and physiology from HGPPS patients suggested that ROBO3 is necessary to permit midline crossing of certain populations of commissural neurons.

7. Abu-Amero KK, al Dhalaan H, al Zayed Z, Hellani A, Bosley TM. Five new consanguineous families with horizontal gaze palsy and progressive scoliosis and novel ROBO3 mutations. J Neurol Sci. 2009; 276(1-2):22-26. [PubMed: 18829051]

8. Amouri R, Nehdi H, Bouhlal Y, Kefi M, Larnaout A, Hentati F. Allelic ROBO3 heterogeneity in Tunisian patients with horizontal gaze palsy with progressive scoliosis. Journal of molecular neuroscience : MN. 2009; 39(3):337-341. [PubMed: 19633821]

9. Abu-Amero KK, Kapoor S, Hellani A, Monga S, Bosley TM. Horizontal gaze palsy and progressive scoliosis due to a deleterious mutation in ROBO3. Ophthalmic Genet. 2011; 32(4):231-236. [PubMed: 21592015]

10. Ng AS, Sitoh YY, Zhao Y, Teng EW, Tan EK, Tan LC. Ipsilateral stroke in a patient with horizontal gaze palsy with progressive scoliosis and a subcortical infarct. Stroke. 2011 ; 42(1):e1e3. [PubMed: 21088243]

11. Volk AE, Carter O, Fricke J, Herkenrath P, Poggenborg J, Borck G, Demant AW, Ivo R, Eysel P, Kubisch C, Neugebauer A. Horizontal gaze palsy with progressive scoliosis: three novel ROBO3 mutations and descriptions of the phenotypes of four patients. Mol Vis. 2011; 17:1978-1986. [PubMed: 21850172]

12. Sicotte NL, Salamon G, Shattuck DW, Hageman N, Rub U, Salamon N, Drain AE, Demer JL, Engle EC, Alger JR, Baloh RW, et al. Diffusion tensor MRI shows abnormal brainstem crossing fibers associated with ROBO3 mutations. Neurology. 2006; 67(3):519-521. [PubMed: 16894121]

13. Haller S, Wetzel SG, Lutschg J. Functional MRI DTI and neurophysiology in horizontal gaze palsy with progressive scoliosis. Neuroradiology. 2008; 50(5):453-459. [PubMed: 18214457]

14. Otaduy MC, Leite Cda C, Nagae LM, Pinho Mda C, Bueno C, Reed UC, Kok F. Further diffusion tensor imaging contribution in horizontal gaze palsy and progressive scoliosis. Arq Neuropsiquiatr. 2009; 67(4):1054-1056. [PubMed: 20069218]

15. Avadhani A, Ilayaraja V, Shetty AP, Rajasekaran S. Diffusion tensor imaging in horizontal gaze palsy with progressive scoliosis. Magn Reson Imaging. 2010; 28(2):212-216. [PubMed: 20071118]

16. Camurri L, Mambetisaeva E, Sundaresan V. Rig-1 a new member of Robo family genes exhibits distinct pattern of expression during mouse development. Gene Expr Patterns. 2004; 4(1):99-103. [PubMed: 14678835]

17. Sabatier C, Plump AS, Le M, Brose K, Tamada A, Murakami F, Lee EY, Tessier-Lavigne M. The divergent Robo family protein Rig-1/Robo3 is a negative regulator of slit responsiveness required for midline crossing by commissural axons. Cell. 2004; 117(2):157-169. [PubMed: 15084255] . ** This report established that Robo3 is required for commissural axons to cross the spinal cord and hindbrain midline in mice. 
18. Chen Z, Gore BB, Long H, Ma L, Tessier-Lavigne M. Alternative splicing of the Robo3 axon guidance receptor governs the midline switch from attraction to repulsion. Neuron. 2008; 58(3): 325-332. [PubMed: 18466743]

19. Long H, Sabatier C, Ma L, Plump A, Yuan W, Ornitz DM, Tamada A, Murakami F, Goodman CS, Tessier-Lavigne M. Conserved roles for Slit and Robo proteins in midline commissural axon guidance. Neuron. 2004; 42(2):213-223. [PubMed: 15091338]

20. Barber M, Di Meglio T, Andrews WD, Hernandez-Miranda LR, Murakami F, Chedotal A, Parnavelas JG. The role of Robo3 in the development of cortical interneurons. Cereb Cortex. 2009; 19(S1):i22-i31. [PubMed: 19366869]

21. Marillat V, Sabatier C, Failli V, Matsunaga E, Sotelo C, Tessier-Lavigne M, Chedotal A. The slit receptor Rig-1/Robo3 controls midline crossing by hindbrain precerebellar neurons and axons. Neuron. 2004; 43(1):69-79. [PubMed: 15233918]

22. Di Meglio T, Nguyen-Ba-Charvet KT, Tessier-Lavigne M, Sotelo C, Chedotal A. Molecular mechanisms controlling midline crossing by precerebellar neurons. J Neurosci. 2008; 28(25): 6285-6294. [PubMed: 18562598]

23. Bouvier J, Thoby-Brisson M, Renier N, Dubreuil V, Ericson J, Champagnat J, Pierani A, Chedotal A, Fortin G. Hindbrain interneurons and axon guidance signaling critical for breathing. Nat Neurosci. 2010; 13(9):1066-1074. [PubMed: 20680010]

24. Renier N, Schonewille M, Giraudet F, Badura A, Tessier-Lavigne M, Avan P, De Zeeuw CI, Chedotal A. Genetic dissection of the function of hindbrain axonal commissures. PLoS biology. 2010; 8(3):e1000325. [PubMed: 20231872] . ** This paper found that conditional Robo3 ${ }^{-/}$mice have reduced commissural projections in the hindbrain, which results in absence of horizontal gaze and abnormal auditory brainstem responses.

25. Tamada A, Kumada T, Zhu Y, Matsumoto T, Hatanaka Y, Muguruma K, Chen Z, Tanabe Y, Torigoe M, Yamauchi K, Oyama H, et al. Crucial roles of Robo proteins in midline crossing of cerebellofugal axons and lack of their up-regulation after midline crossing. Neural Dev. 2008; 3:29. [PubMed: 18986510]

26. Kuwako KI, Kakumoto K, Imai T, Igarashi M, Hamakubo T, Sakakibara SI, Tessier-Lavigne M, Okano HJ, Okano H. Neural RNA-Binding Protein Musashi1 Controls Midline Crossing of Precerebellar Neurons through Posttranscriptional Regulation of Robo3/Rig-1 Expression. Neuron. 2010; 67(3):407-421. [PubMed: 20696379]

27. Sakakibara S, Nakamura Y, Yoshida T, Shibata S, Koike M, Takano H, Ueda S, Uchiyama Y, Noda T, Okano H. RNA-binding protein Musashi family: roles for CNS stem cells and a subpopulation of ependymal cells revealed by targeted disruption and antisense ablation. Proc Natl Acad Sci U S A. 2002; 99(23):15194-15199. [PubMed: 12407178]

28. Bosley TM, Salih MA, Jen JC, Lin DD, Oystreck D, Abu-Amero KK, MacDonald DB, al Zayed Z, al Dhalaan H, Kansu T, Stigsby B, et al. Neurologic features of horizontal gaze palsy and progressive scoliosis with mutations in ROBO3. Neurology. 2005; 64(7):1196-1203. [PubMed: 15824346]

29. Gallea C, Popa T, Billot S, Meneret A, Depienne C, Roze E. Congenital mirror movements: a clue to understanding bimanual motor control. J Neurol. 2011; 258(11):1911-1919. [PubMed: 21633904]

30. Koerte I, Eftimov L, Laubender RP, Esslinger O, Schroeder AS, Ertl-Wagner B, WahllaenderDanek U, Heinen F, Danek A. Mirror movements in healthy humans across the lifespan: effects of development and ageing. Dev Med Child Neurol. 2010; 52(12):1106-1112. [PubMed: 21039436]

31. Leinsinger GL, Heiss DT, Jassoy AG, Pfluger T, Hahn K, Danek A. Persistent mirror movements: functional MR imaging of the hand motor cortex. Radiology. 1997; 203(2):545-552. [PubMed: 9114119]

32. Cincotta M, Borgheresi A, Balzini L, Vannucchi L, Zeloni G, Ragazzoni A, Benvenuti F, Zaccara G, Arnetoli G, Ziemann U. Separate ipsilateral and contralateral corticospinal projections in congenital mirror movements: Neurophysiological evidence and significance for motor rehabilitation. Mov Disord. 2003; 18(11):1294-1300. [PubMed: 14639670]

33. Farmer SF, Ingram DA, Stephens JA. Mirror movements studied in a patient with Klippel-Feil syndrome. The Journal of physiology. 1990; 428:467-484. [PubMed: 2231422] 
34. Srour M, Riviere JB, Pham JM, Dube MP, Girard S, Morin S, Dion PA, Asselin G, Rochefort D, Hince P, Diab S, et al. Mutations in DCC cause congenital mirror movements. Science. 2010; 328(5978):592. [PubMed: 20431009] . ** This is the first report identifying the genetic basis of congenital mirror movements resulting from mutations in the axon guidance receptor, $D C C$, in two unrelated families.

35. Ferland RJ, Eyaid W, Collura RV, Tully LD, Hill RS, Al-Nouri D, Al-Rumayyan A, Topcu M, Gascon G, Bodell A, Shugart YY, et al. Abnormal cerebellar development and axonal decussation due to mutations in AHI1 in Joubert syndrome. Nat Genet. 2004; 36(9):1008-1013. [PubMed: 15322546]

36. Mayston MJ, Harrison LM, Quinton R, Stephens JA, Krams M, Bouloux PM. Mirror movements in X-linked Kallmann's syndrome. I.A neurophysiological study. Brain. 1997; 120(7):1199-1216. [PubMed: 9236631]

37. Vulliemoz S, Raineteau O, Jabaudon D. Reaching beyond the midline: why are human brains cross wired? Lancet Neurol. 2005; 4(2):87-99. [PubMed: 15664541]

38. Depienne C, Cincotta M, Billot S, Bouteiller D, Groppa S, Brochard V, Flamand C, Hubsch C, Meunier S, Giovannelli F, Klebe S, et al. A novel DCC mutation and genetic heterogeneity in congenital mirror movements. Neurology. 2011; 76(3):260-264. [PubMed: 21242494] . * This paper reports a third $D C C$ mutation underlying congenital mirror movements, but also describes two families that do not harbor $D C C$ mutations, suggesting congenital mirror movements is a genetically heterogeneous disorder.

39. Djarmati-Westenberger A, Bruggemann N, Espay AJ, Bhatia KP, Klein C. A novel DCC mutation and genetic heterogeneity in congenital mirror movements. Neurology. 2011; 77(16):1580. [PubMed: 22006891]

40. Stein E, Zou Y, Poo M, Tessier-Lavigne M. Binding of DCC by netrin-1 to mediate axon guidance independent of adenosine A2B receptor activation. Science. 2001; 291(5510):1976-1982. [PubMed: 11239160]

41. Fazeli A, Dickinson SL, Hermiston ML, Tighe RV, Steen RG, Small CG, Stoeckli ET, KeinoMasu K, Masu M, Rayburn H, Simons J, et al. Phenotype of mice lacking functional Deleted in colorectal cancer (Dcc) gene. Nature. 1997; 386(6627):796-804. [PubMed: 9126737]

42. Finger JH, Bronson RT, Harris B, Johnson K, Przyborski SA, Ackerman SL. The netrin 1 receptors Unc5h3 and Dcc are necessary at multiple choice points for the guidance of corticospinal tract axons. The Journal of Neuroscience. 2002; 22(23):10346-10356. [PubMed: 12451134]

43. Rabe N, Gezelius H, Vallstedt A, Memic F, Kullander K. Netrin-1-dependent spinal interneuron subtypes are required for the formation of left-right alternating locomotor circuitry. The Journal of Neuroscience. 2009; 29(50):15642-15649. [PubMed: 20016078]

44. Dottori M, Hartley L, Galea M, Paxinos G, Polizzotto M, Kilpatrick T, Bartlett PF, Murphy M, Kontgen F, Boyd AW. EphA4 (Sek1) receptor tyrosine kinase is required for the development of the corticospinal tract. Proc Natl Acad Sci U S A. 1998; 95(22):13248-13253. [PubMed: 9789074]

45. Iwasato T, Katoh H, Nishimaru H, Ishikawa Y, Inoue H, Saito YM, Ando R, Iwama M, Takahashi $\mathrm{R}$, Negishi M, Itohara S. Rac-GAP alpha-chimerin regulates motor-circuit formation as a key mediator of ephrinB3/EphA4 forward signaling. Cell. 2007; 130(4):742-753. [PubMed: 17719550]

46. Kullander K, Butt SJ, Lebret JM, Lundfald L, Restrepo CE, Rydstrom A, Klein R, Kiehn O. Role of EphA4 and EphrinB3 in local neuronal circuits that control walking. Science. 2003; 299(5614): 1889-1892. [PubMed: 12649481]

47. Kullander K, Croll SD, Zimmer M, Pan L, McClain J, Hughes V, Zabski S, DeChiara TM, Klein $\mathrm{R}$, Yancopoulos GD, Gale NW. Ephrin-B3 is the midline barrier that prevents corticospinal tract axons from recrossing, allowing for unilateral motor control. Genes Dev. 2001; 15(7):877-888. [PubMed: 11297511]

48. Mackey DA, Chan WM, Chan C, Gillies WE, Brooks AM, O'Day J, Engle EC. Congenital fibrosis of the vertically acting extraocular muscles maps to the FEOM3 locus. Hum Genet. 2002; 110(5): 510-512. [PubMed: 12073023]

49. Tischfield MA, Baris HN, Wu C, Rudolph G, Van Maldergem L, He W, Chan WM, Andrews C, Demer JL, Robertson RL, Mackey DA, et al. Human TUBB3 mutations perturb microtubule dynamics, kinesin interactions, and axon guidance. Cell. 2010; 140(1):74-87. [PubMed: 
20074521] . ** The authors show that 8 different missense mutations in beta-III tubulin (TUBB3) cause the eye movement disorder CFEOM3 due to aberrant guidance of the oculomotor nerve. Additional mutation-specific neurological disorders are observed in human patients, which appear to be due to axon miswiring rather than general defects in cortical architecture.

50. Demer JL, Clark RA, Tischfield MA, Engle EC. Evidence of an asymmetrical endophenotype in congenital fibrosis of extraocular muscles type 3 resulting from TUBB3 mutations. Invest Ophthalmol Vis Sci. 2010; 51(9):4600-4611. [PubMed: 20393110]

51. Jiang YQ, Oblinger MM. Differential regulation of beta III and other tubulin genes during peripheral and central neuron development. J Cell Sci. 1992; 103(3):643-651. [PubMed: 1478962]

52. Chen SY, Huang PH, Cheng HJ. Disrupted-in-Schizophrenia 1-mediated axon guidance involves TRIO-RAC-PAK small GTPase pathway signaling. Proc Natl Acad Sci U S A. 2011; 108(14): 5861-5866. [PubMed: 21422296]

53. Geschwind DH, Levitt P. Autism spectrum disorders: developmental disconnection syndromes. Curr Opin Neurobiol. 2007; 17(1):103-111. [PubMed: 17275283]

54. Nie D, Di Nardo A, Han JM, Baharanyi H, Kramvis I, Huynh T, Dabora S, Codeluppi S, Pandolfi PP, Pasquale EB, Sahin M. Tsc2-Rheb signaling regulates EphA-mediated axon guidance. Nat Neurosci. 2010; 13(2):163-172. [PubMed: 20062052] 


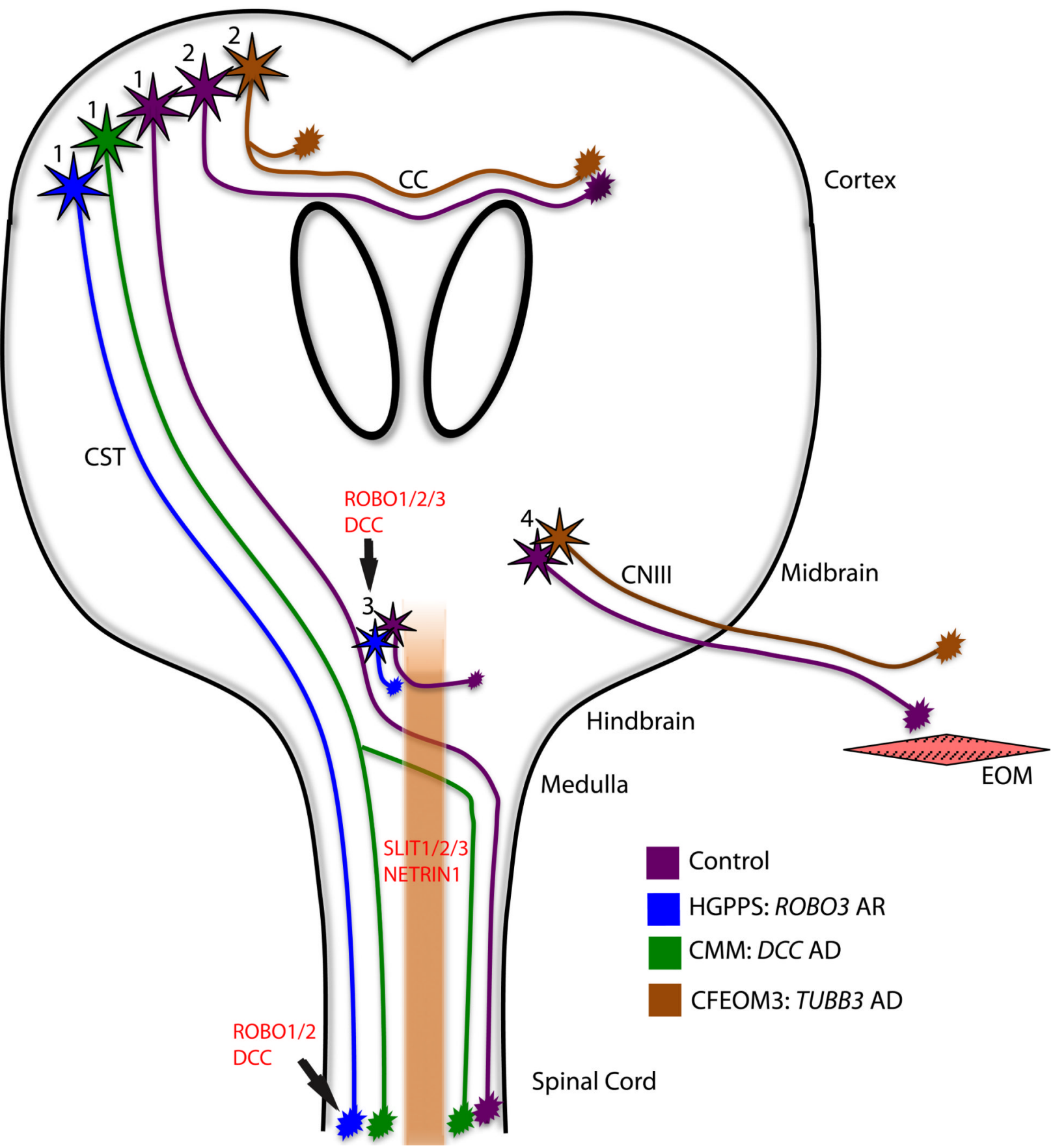

Figure 1.

Schematic of axon guidance defects in HGPPS, CMM, and CFEOM3. With normal guidance (purple): corticospinal tract (CST) axons navigate from the motor cortex to the spinal cord, decussating in the medulla (cell bodies labeled ' 1 '); corpus callosum (CC) and anterior commissure axons cross from one hemisphere to the other (cell bodies labeled '2'); interneuron populations decussate in the hindbrain (cell bodies labeled ' 3 '); and oculomotor axons extend to their target extraocular muscles (EOM, cell bodies labeled '4'). In HGPPS (blue), CST and hindbrain interneuron axons fail to decussate, resulting in ipsilateral projections. In CMM (green), it is proposed but not proven that while some CST axons decussate appropriately, others fail to do so and project ipsilaterally. In CFEOM3 (brown), 
there is variable thinning of the $\mathrm{CC}$ and anterior commissure axons, supporting abnormal guidance of these axonal tracts and the oculomotor nerve (CNIII) has abnormal guidance, resulting in the dysinnervation of EOM. $\mathrm{AR}=$ autosomal recessive; $\mathrm{AD}=$ autosomal dominant. 

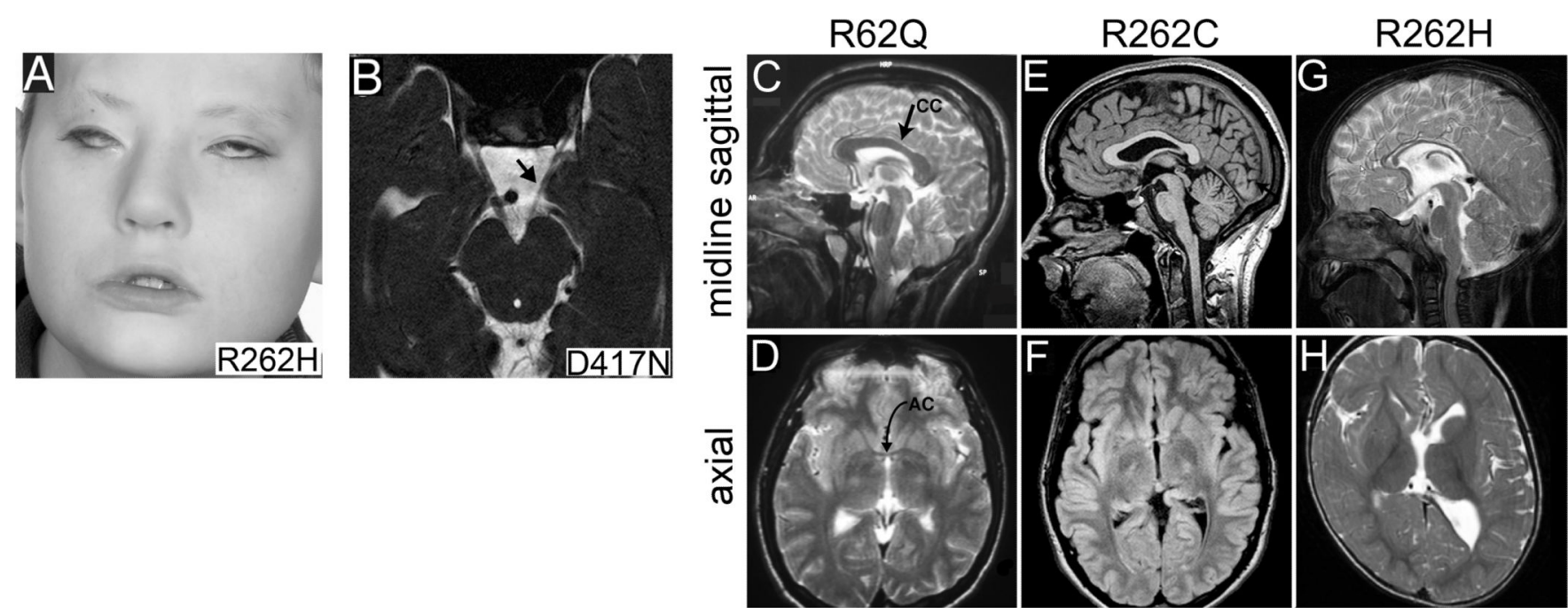

Figure 2.

$T U B B 3$ mutation-specific abnormalities in white matter tracts and basal ganglia. (A) Photograph of a child harboring a TUBB3 R262H amino acid substitution who exhibits severe CFEOM3 and facial weakness. (B) Brainstem MRI from a patient with predominantly left-sided CFEOM3 reveals unilateral hypoplasia of the left oculomotor nerve (arrow; D417N substitution). (C-H) Sagittal and axial MR images from individuals harboring R62Q, R262C, and R262H TUBB3 substitutions as indicated. (C,D) R62Q results in normal appearance of the corpus callosum (CC) and anterior commissure (AC); (E,F) R262C causes $C C$ posterior thinning $(\mathrm{E})$ and $\mathrm{AC}$ hypoplasia $(\mathrm{F}) ;(\mathrm{G}, \mathrm{H})$ while $\mathrm{R} 262 \mathrm{H}$ causes $\mathrm{CC}$ hypoplasia $(\mathrm{G}), \mathrm{AC}$ agenesis and dysmorphic basal ganglia $(\mathrm{H})$. (Reprinted, with permission, from [49]). 